\title{
Deuda Saldada: Franco, el régimen y la guerra colonial portuguesa
}

\author{
María José Tíscar Santiago \\ Doctora en Historia Contemporánea \\ Instituto de Estudios Ibéricos
}

\section{Debt Cancelled: Franco, the Regime and the Portuguese Colonial War}

\begin{abstract}
RESUMEN
El papel desempeñado por la España de Franco en la Guerra Colonial portuguesa, como apoyo permanente en el terreno militar y diplomático, tuvo como base el entendimiento político de los regímenes ibéricos y revistió formas homogéneas a las de la ayuda portuguesa al bando nacional en la Guerra Civil española. Existen evidencias documentales que permiten afirmar que el Franquismo saldó la deuda contraída con el Portugal salazarista y que el Pacto Ibérico fue el marco jurídico que le dio cobertura.
\end{abstract}

\section{PALABRAS CLAVE}

Guerra Colonial portuguesa, Guerra Civil española, Pacto Ibérico, Conferencias de Ios Estados Mayores Peninsulares, OTAN, Salazarismo, Franquismo.

\begin{abstract}
The role of Franco's Spain in the Portuguese Colonial War, as a continuous support in the military and diplomatic field, was based on the political understanding of the Iberian regimes and involved homogeneous forms of the Portuguese aid to the national side in the Spanish civil War. There is documentary evidence to support the conclusion that the Franquism settled the debt with Salazar's Portugal and the Iberian Pact was the legal framework that gave coverage.
\end{abstract}

KEY WORDS

Portuguese Colonial War, Spanish Civil War, Iberian Pact, Peninsular Staffs Conference, NATO, Salazarism, Franquism.

La intervención del Portugal salazarista en la Guerra Civil española es conocida y forma parte del acervo historiográfico ibérico. Por el contrario, es aún bastante desconocida la contribución del gobierno de la España franquista a Portugal durante la guerra colonial que se extendió desde 1961 hasta 1974.

Además de tener carácter permanente a lo largo de toda la contienda, la ayuda española revistió casi las mismas fórmulas que las aportadas por el salazarismo al 
bando franquista entre 1936 y 1939. Podemos incluso decir que en algún ámbito, como el político-diplomático, la contribución española a la política ultramarina portuguesa fue más amplia, variada y particularmente arriesgada por cuanto suponía, además de contrariar las normas y resoluciones internacionales, dificultar la propia acción exterior española, que había optado por una alineación con las tendencias dominantes en el sistema internacional proclives a la descolonización. El apoyo a Portugal, representaba, por lo tanto, una contradicción con respecto a sus propios intereses en política exterior, orientados hacia la amistad con los nuevos estados que formaban el creciente grupo afroasiático y con las antiguas colonias americanas.

Así pues, cabría preguntarse ¿se produjo un cierto grado de «satelitismo» en la colaboración española durante las guerras del ultramar portugués forzado por la deuda contraída por el franquismo con el Portugal salazarista? Por imperativo de la propia naturaleza de las relaciones bilaterales, debemos plantearnos otro interrogante ¿esperaba el que había sido beneficiario de la ayuda del Portugal salazarista para conseguir la victoria que lo había llevado al poder seguir recibiendo apoyo para un reconocimiento internacional que nunca llegó a ser pleno? O planteándolo de manera más precisa ¿sería el Portugal salazarista un sustento político en la particular cruzada de Franco por ser homologado a los generales victoriosos contra el fascismo que luego se organizaron contra el comunismo en la OTAN, donde él no conseguía ser admitido por veto político a pesar de contar con el expreso apoyo de su componente militar?

La documentación política, militar y diplomática hoy disponible ofrece suficiente información para proponer una respuesta a estas preguntas y también para matizar o incluso sugerir una revisión de algunos asertos que se han establecido sobre tres aspectos de las relaciones peninsulares durante este periodo. Uno de ellos se refiere al supuesto convencimiento de Salazar, especialmente tras la última entrevista con Franco, de que no cabía esperar ayuda española en las guerras africanas y que ha venido sirviendo de base para dar por hecho que no existió ${ }^{1}$. El segundo tiene que ver con la supuesta negativa española a autorizar el paso por territorio nacional de las tropas portuguesas destinadas, dentro de la estrategia diseñada por la OTAN, a contribuir a la defensa de Europa y que se conoció como

1 Esta afirmación suele basarse en las frecuentes quejas del ministro Franco Nogueira hacia Madrid cada vez que el apoyo español no respondía con plena satisfacción a lo expresamente pedido por Lisboa. Se toma como referencia inicial de la supuesta inhibición española de los problemas portugueses en África lo que Salazar habría comentado a sus colaboradores al regreso del último encuentro en Mérida a propósito del comunicado final, cuyo tenor habría hecho suponer a muchos que no todo había ido bien entre ambos: «Franco fala pouco, a política espanhola é difícil, não podemos confiar demasiado, e um comunicado muito extenso teria de dizer mais o que eu disse do que aquilo que Franco disse". Pero este comentario se refiere a las características del comunicado final del encuentro en el que, según el propio biógrafo de Salazar, éste habría hablado extensamente a Franco sobre la situación en el África portuguesa y la actuación que su gobierno se proponía llevar a cabo en ella. Sin embargo, sobre la posición de España a este respecto Franco Nogueira deja clara constancia del mantenimiento del compromiso de ayuda del gobierno franquista: «Salazar expõe com largueza a política de África que Portugal pratica; e Franco declara que a compreende e a apoia na ONU, e no plano bilateral, em ajuda de que o governo português necessite». Ver FRANCO NOGUEIRA, A., Salazar Vol. V. A Resistência (19581964), Porto, Civilização Editora, 1988, p.483-485. 
División SHAPE o División Nun' Álvares. ${ }^{2}$ Y el tercer aspecto se refiere a la afirmación de que las Conferencias de los Estados Mayores Peninsulares (CEMP) que coordinaron las relaciones militares ibéricas a partir de 1954 fueron simples eventos sociales que no se plasmaron en acuerdos efectivos ${ }^{3}$.

Estas cuestiones están íntimamente relacionadas pues todas ellas responden al uso que de los mecanismos del Pacto Ibérico hicieron los gobernantes de Portugal y de España dentro del bloque occidental en los tiempos de la Guerra Fría, marco histórico general donde se insertan tanto la creación de la OTAN, con la exclusión de la España franquista, como la guerra colonial portuguesa.

Veremos en primer lugar el origen de este planteamiento, que es la intervención portuguesa en la Guerra Civil española culminada con la firma del Tratado de Amistad y no Agresión pocos días antes de que el general Franco emitiera el último parte de guerra. A continuación haremos una breve síntesis de las características de este instrumento jurídico-político que sirvió de base a las relaciones hispano-portuguesas y que se utilizó como referencia para actuaciones fuera del ámbito peninsular aunque, en un principio, estaba limitada a él. Por último, daremos cuenta de manera muy resumida, de las principales formas que adoptó el apoyo de Franco a Salazar en esos largos años de guerra en África y que se mantuvo con Marcello Caetano sin grandes cambios, teniendo siempre por cobertura el Pacto Ibérico.

\section{EL PRECEDENTE: LA AYUDA DEL PORTUGAL SALAZARISTA AL BANDO NACIONAL EN LA GUERRA CIVIL ESPAÑOLA}

La ayuda portuguesa al bando nacional durante la Guerra Civil española se materializó, según está asentado tanto en la historiografía portuguesa como en la española, en un «apoyo militar humilde, una cobertura logística importante, un respaldo propagandístico de primer orden y un fundamental auxilio político-diplomático» ${ }^{4}$.

\footnotetext{
2 «A Divisão Nun' Álvares fora formada para combater além-Pirinéus o inimigo russo e comunista. Fora atribuída como reserva ao AFCENT (Forças Aliadas do Centro da Europa), um comando subordinado ao SACEUR (Supremo Comando Aliado da Europa). Em caso de conflito, estacionaria na região de Bordéus (França). O seu transporte, porém, era terrestre, e nunca Espanha o consentiu» THEMUDO BARATA, M. y SEVERIANO TEIXEIRA, N. (Dir.) Nova História Militar de Portugal, Lisboa, Circulo de Leitores, 2004, volumen 4, p. 170.

3 «O exito destas conferências não foi muito grande, pois estiveram marcadas pelo receio português: sempre se temeu que um maior estreitamento pudesse tornar-se negativo para o mais débil e vulnerável dos dois paises» BELO, J. E. Nunes, Cooperação Portugal-Espanha: contribuição para um estudo das relações bilaterais (1864-1986), Lisboa, Instituto Superior de Ciências Sociais e Políticas, 1987 p. 52. «Para mais, as precauções anti-espanholas no seio do Exército eram maiores que em outras esferas, porque continuavam a considerar a Espanha como um inimigo potencial, em virtude do nunca desaparecido receio propiciado pelo fenómeno iberista» JIMÉNEZ REDONDO, J. C., Franco e Salazar. As relações luso-espanholas durante a Guerra Fria, Lisboa, Assírio \& Alvim, 1996, p. 190.

${ }^{4}$ Ver, TORRE GÓMEZ, H. de la, «La Relación hispano-portuguesa en el siglo XX» en TUSELL, J., AVILÉS, J. y PARDO, R. (eds.), La política exterior de España en el siglo XX, Madrid, UNED, Biblioteca Nueva, 2000, p. 168. DELGADO, I., Portugal e a Guerra Civil de Espanha (1931-1936), Lisboa, Europa-América, 1981.
} 
La modesta ayuda militar portuguesa tuvo su manifestación más visible en el envío de los «Viriatos» y de misiones de observación pero la contribución más valiosa en este campo se dio en forma de apoyo logístico, garantizando al mismo tiempo la seguridad en la línea fronteriza. Se afirmó ya entonces que Portugal se había convertido en la principal zona de operaciones de los rebeldes ${ }^{5}$ a quienes se facultaban desde condiciones para operaciones aéreas, paso de tropas, armamento y abastecimiento diverso de material de guerra por territorio portugués, hasta facilidades para el reclutamiento de voluntarios a favor del bando nacional. Está igualmente establecido que fue considerable el apoyo policial capturando y entregando a las autoridades militares refugiados políticos que creyeron poder ponerse a salvo de la represión en las zonas donde triunfaban los sublevados al cruzar la frontera ignorando los acuerdos secretos en este sentido entre Lisboa y Burgos. ${ }^{6}$

En cuanto a la ayuda político-diplomática recibida por el bando franquista destacan la labor obstruccionista de la diplomacia portuguesa en el Comité de No Intervención, además del temprano reconocimiento de facto del gobierno de Burgos y la celeridad en la acreditación de embajadores ${ }^{7}$. Se asegura también que este apoyo político-diplomático tendría una contrapartida pues sería la Guerra Civil española la que daría a Oliveira Salazar la oportunidad de afirmarse en las cuestiones internacionales y que la «amistad peninsular» se convertiría, junto con la vieja alianza luso-británica y la automarginación frente a los contenciosos de la política europea continental, en uno de los pilares de la política exterior del Estado Novo. De hecho, se puede decir que el Presidente del Consejo portugués desempeñó la función de intermediario de la España franquista no sólo en la Guerra Mundial que siguió a la victoria del bando nacional sino también en la posterior Guerra Fría, primero cuando se planteó «la cuestión española» y después durante la exclusión que aquélla sufrió al crearse la OTAN.

Es pues durante la participación portuguesa en la Guerra española cuando se produce un entendimiento de Estado entre el «Régimen del 18 de Julio» que se establece en España y el Estado Novo portugués. Salazar había apostado desde el primer momento por una victoria del bando nacionalista y llegó a dar pública muestra de sus deseos de anudar con los que quería vencedores una alianza duradera que fuera instrumento de garantía de seguridad para ambos regímenes: «oxalá a vitória da verdadeira Espanha nacionalista possa em breve constituir base indestrutível dessa política de recíproca segurança» ${ }^{8}$.

${ }^{5}$ Ver MNE, Dez Anos de Política Externa. A Nação Portuguesa e a Segunda Guerra Mundial. 1936-1947, Vol II, pp. 324-235.

6 Ver DELGADO, I., Portugal e a guerra civil de Espanha, Lisboa, Publicações Europa-América 1980, pp. 86-92.

7 Pedro Teotónio Pereira fue designado por Salazar como agente especial junto del gobierno de Franco partiendo para Salamanca en una misión diplomática que se inició el 19 de enero de 1938. Una vez realizado el reconocimiento de iure del gobierno franquista, el 11 de mayo de 1938, Teotónio Pereira presentó sus cartas credenciales a Franco como embajador de Portugal el 24 de junio del mismo año.

${ }^{8}$ Discurso de Oliveira Salazar proferido en la Emissora Nacional el 27 de octubre de 1938, «Preocupação da paz e preocupação da vida» en Salazar Discursos e Notas Políticas III: 1938-1945. Coimbra, 
Esa política de seguridad recíproca anhelada por Salazar tuvo su primera manifestación jurídica en el acuerdo firmado en Lisboa el 17 de marzo de 1939 entre el embajador del gobierno de Burgos, Nicolás Franco, y el ministro de Asuntos Exteriores portugués, el propio Oliveira Salazar, tras una apresurada negociación por el temor que surgió en el gobierno del bando nacional de que la guerra europea, que se sentía inminente tras la extensión de la crisis de los Sudetes, encontrara sin finiquitar la contienda española, dando así una oportunidad a los deseos del presidente del gobierno republicano Juan Negrín. Con este acuerdo se creaba un instrumento político destinado, en un principio, a la neutralización peninsular ante la guerra europea que se aproximaba pero, como veremos, su contenido se amplió posteriormente para los usos más variados, llegando a incluir la contribución española a la guerra del ultramar portugués.

\section{EL MARCO JURIIDICO-POLÍTICO: EL PACTO IBÉRICO}

El instrumento jurídico-político conocido como Pacto Ibérico o Pacto Peninsular englobaba el Tratado de Amistad y no Agresión entre España y Portugal de 1939 y los sucesivos protocolos adicionales que se le fueron acrecentando en el transcurso del tiempo para mantener su vigencia adaptada a las necesidades de cada coyuntura: el Protocolo Adicional de 1940, el II Protocolo Adicional de 1948 y el III Protocolo Adicional de 1970, momento en el que se propuso por parte portuguesa la firma de un protocolo secreto en materia de colaboración anti subversiva a la que España no accedió. El Pacto fue señalado por el propio Ministerio de Asuntos Exteriores español como la horma externa de la entente de estadistas que haría funcionar la Península Ibérica, a pesar de las divergencias en política interior y exterior, como una unidad estratégica en el sistema internacional no sólo desde el punto de vista político sino también desde el punto de vista militar.

Las estrechas relaciones durante el Estado Novo y el Franquismo empiezan con una guerra a causa de la cual se aísla internacionalmente al gobierno de España y terminan con otra guerra que ocasiona una situación similar a Portugal.

El carácter de «alianza para la supervivencia mutua» que estas relaciones tuvieron desde el principio hasta el final se manifiesta claramente en el hecho de que no se llegaran a realizar proyectos de integración ni de carácter económico, ni social o cultural aunque hubo algunos intentos por parte española, siempre aceptados pero retardados hasta la extinción por el lado lusitano. Así pues, la colaboración hispanoportuguesa nacida de la guerra civil se ciñó al puro campo de la acción exterior según cada estadista fuera necesitando el auxilio vecino al albur de los vientos de la Historia. Es en esta constante donde primero se va a insertar la contrapartida permanentemente esperada por Franco, la admisión en la OTAN, y donde después se va a abrigar la ayuda española al mantenimiento de Portugal en África.

Coimbra editora, 1943. 
No obstante la euforia de los primeros años, a partir de 1948 la entente ibérica empezó a experimentar sus primeros episodios de malestar cuando la posición portuguesa, de perfecta integración en el nuevo esquema de las relaciones internacionales, contrastaba ostentosamente con el apartamiento de España del concierto de las naciones. Se podría decir que en este ámbito la única situación que los regímenes peninsulares mantuvieron en común fue su imposibilidad de acceso a la Asamblea General de las Naciones Unidas, que conseguirán al mismo tiempo en 1955. Por ello, aunque los dos regímenes ibéricos se podrían considerar anomalías políticas en la Europa occidental liberada del fascismo, el grado de esa anomalía que representaba cada uno de ellos no tenía la misma percepción para los otros estados, pues a uno se lo integraba y al otro se lo rechazaba. De la misma manera será percibida después como anomalía, no de constitución política sino de constitución colonial, la pertinacia de Salazar que supuso el inicio de «la cuestión portuguesa» en los organismos internacionales a partir de 1960.

Así pues, las relaciones ibéricas siguieron siendo estrechas por la imperiosa necesidad que tenía una España aislada de conservar las escasas relaciones exteriores que le permitían la retirada de embajadores a raíz de la recomendación de las Naciones Unidas de 1946, aunque muchas legaciones se mantuvieran activas a nivel de encargado de negocios. La «ventana portuguesa ${ }^{9}$ sería vital para España durante la década que medió entre el final de la Guerra mundial y la forzada admisión del régimen franquista en el concierto internacional en el marco de la Guerra fría. ${ }^{10} \mathrm{La}$ fortaleza de las relaciones se mantuvo, pero con beneficio en sentido inverso, favoreciendo ahora a Portugal, durante el aislamiento producido a partir de 1961. En este periodo de condenas en las Naciones Unidas y rupturas diplomáticas con Portugal, el gobierno español fue un gran apoyo tanto en forma de ventana a los afroasiáticos como de cobertura de procedimientos poco confesables en el marco de la guerra antisubversiva que el Estado luso libraba en sus colonias contra las guerrillas nacionalistas asentadas en países limítrofes, en los que se realizaban intervenciones contrarias a las normas del derecho internacional y a la propia tradición de los usos diplomáticos portugueses.

\section{LA INSERCIÓN DEL PACTO IBÉRICO EN LA ESTRATEGIA DE LA OTAN}

La disparidad de situaciones en el ámbito internacional de la posguerra mundial tuvo su primera consecuencia en las relaciones peninsulares con la invitación cursada a Lisboa para firmante del Tratado de Washington. Como obligaban los convenios peninsulares, antes de la incorporación de Portugal a la OTAN se mantuvieron conver-

9 Ver, TORRE GÓMEZ, H., de la, «La Relación hispano-portuguesa en el siglo XX» en TUSELL, J., AVILÉS, J. y PARDO, R. (eds.), La política exterior de España en el siglo XX, Madrid, UNED, Biblioteca Nueva, 2000, p. 174.

10 Ver JIMENEZ REDONDO, J. C., Franco e Salazar. As relações luso-espanholas durante a guerra fría, Lisboa, Assírio e Alvim, 1996. 
saciones entre Madrid y Lisboa sobre los efectos que causaría esta adhesión en el Pacto Ibérico y el gobierno portugués presentó, en sus conversaciones con los aliados anglosajones impulsores del nuevo pacto político-militar, una reserva relativa a la ausencia de España, que Salazar consideraba absurda por romper la unidad estratégica de la Península. Pero las gestiones fueron inútiles por la inconveniencia política que representaba aquel régimen instalado con la ayuda del nazismo y del fascismo.

Esta ansia española por conseguir la integración en la Alianza Atlántica y la intermediación portuguesa en su apoyo será otra constante de las relaciones políticas entre el Salazarismo y el Franquismo mientras Franco mantenga la esperanza de que se presente la coyuntura propicia para hacerse acreedor a recibir él también la misma invitación que había sido cursada a Salazar en 1948.

El enfado español por el golpe que suponía quedar fuera del Pacto Atlántico impelió al gobierno de Madrid a invocar el Tratado de Amistad y No Agresión de 1939 aduciendo los riesgos que para España entrañaba la inclusión de Portugal, que atraería las hostilidades del bloque oriental hasta sus fronteras mientras quedaba excluida del sistema de defensa contra las divisiones soviéticas que eventualmente podrían llegar a alcanzar la Península, pues era ésta, en principio, la justificación para la creación de la Organización Atlántica. Pero las alegaciones españolas fueron rechazadas aduciendo que tanto el Pacto del Atlántico como el Pacto Ibérico serían, según el gobierno portugués, perfectamente compatibles. Es de notar, sin embargo, que ya desde el momento en que se trató de la ratificación del Pacto del Atlántico en la Asamblea Nacional, Salazar, aunque aparentemente satisfecho de la integración de Portugal en el sistema defensivo del bloque occidental, presentía la gran limitación que para su gobierno tenía la Alianza por la exclusión del Ultramar. Las consecuencias de ello, en efecto, se materializaron más tarde, en la guerra colonial, para la que oficialmente no se permitió a Portugal echar mano de las ventajas militares de la Organización Atlántica. Por el contrario, sí pudo valerse, entre otras, de las que podían abrigarse en el Pacto lbérico.

España, por su parte, tuvo también su experiencia sobre las limitaciones de las ventajas militares de los Acuerdos con los Estados Unidos con ocasión de la Guerra de lfni, en la que tampoco se le permitió el uso del material americano por más indispensable que le fuese, lo que dejó al ejército español en una situación de debilidad de medios que fue especialmente sensible en la actuación de la fuerza aérea e hizo necesaria una intervención francesa para mantener la posición.

Pero la situación cambió con el estallido de la Guerra de Corea cuando el Consejo de Seguridad de las Naciones Unidas aceptó, por petición del gobierno del presidente Truman, formar una fuerza internacional para intervenir en apoyo de Corea del Sur con quien España había establecido relaciones diplomáticas este mismo año. Al verse abocada a concentrar sus esfuerzos en el Pacífico, la estrategia del Pentágono 
y del Departamento de Estado consistió en reforzar indirectamente el flanco occidental de Europa estableciendo más bases militares, coyuntura que decidió definitivamente a los aliados anglosajones a cambiar su política contra el régimen franquista. ${ }^{11}$

El atribulado Franco se había convertido en un gobernante relajado que veía con optimismo su permanencia en el poder, el malestar español por la no admisión en la OTAN parecía superado y una nueva perspectiva se abría en el horizonte. Para tratar de la nueva coyuntura, el generalísimo español invitó a Salazar a hacer un viaje por Galicia que fue inmediatamente retribuido por el Presidente del Consejo portugués con una continuación en el Norte de Portugal. Esos mismos días, el mariscal Montgomery, Jefe supremo adjunto de la OTAN en Europa, aprovechando una visita de inspección a los Pirineos franceses, se entrevistó en San Juan de Luz con militares españoles, "cuya opinión sobre los planes estratégicos de la defensa occidental espera conocer con un vivo interés. Estas entrevistas, de resultar satisfactorias, pudieran ser el prólogo a una conferencia oficial más amplia que se celebraría dentro de tres meses» ${ }^{12}$. La conclusión del periodismo conservador europeo sobre este encuentro fue que la incorporación de la España franquista a la normalidad político-diplomática era una necesidad en la que estaban de acuerdo la mayor parte de las potencias occidentales salvo algunas que seguían prisioneras de una parte de su opinión pública que la continuaba rechazando, como sería el caso del laborismo inglés o del socialismo francés, porque podría tener repercusiones electorales no convenientes.

Comenzaron, en efecto, las entrevistas trilaterales entre militares anglosajones, portugueses y españoles que desembocaron, en el nivel político, en la Conferencia de Ciudad Rodrigo en 1952. Allí se decidió adaptar el Pacto Ibérico a las necesidades estratégicas de la OTAN, de tal manera que España, aún sin pertenecer a su estructura, sería indirectamente incluida en su operativo militar en espera de mejores momentos para que políticamente pudiera ser factible una integración más visible. Para organizar esta parcial integración tangencial del Pacto Ibérico en la estrategia de la Alianza Atlántica, su mando europeo promovió encuentros periódicos entre los estados mayores respectivos cuya composición y dinámica se diseñaron en el Parador de Gredos en el verano de $1952^{13}$.

11 HUGET, M., «La política exterior del Franquismo (1939-1975) en PEREIRA, J.C. (coord.) La política exterior de España (1800-2003), Barcelona, Ariel, 2003, p. 503.

12 Ver La Vanguardia Española de 14 de septiembre de 1950, p. 7.

13 Para delinear los aspectos concretos en los que se materializarían los pactos políticos en el ámbito militar, tomados a partir de las instrucciones de los mandos anglosajones de la OTAN, se reunió en julio de 1952 la Conferencia de la Sierra de Gredos. A partir de ella, el Pacto lbérico tuvo un órgano permanente de coordinación militar conocido como Conferencias de los Estados Mayores Peninsulares (CEMP), que se celebraron con periodicidad anual alternativamente en Madrid y Lisboa. Estos encuentros militares comenzaron a funcionar partiendo del Memorandum que el General Júlio Botelho Moniz, Jefe de Estado Mayor de las Fuerzas Armadas portuguesas, presentó como guía de estudio en la primera reunión en enero de 1954. En este documento se encaraba en todas sus facetas el problema de la colaboración peninsular en materia de defensa integrado en la estrategia de la Alianza Atlántica. 


\section{EL MECANISMO DE COORDINACIÓN MILITAR IBÉRICA: LAS CEMP}

A partir de la institucionalización de las reuniones periódicas de los Estados Mayores del Pacto Ibérico ${ }^{14}$ (CEMP), las conversaciones que se siguieron entre España y Portugal, tanto en la cumbre política con encuentros entre Salazar y Franco como entre las autoridades castrenses de cada uno de los estados y representantes militares de los Estados Unidos o del Reino Unido, tratarán de atenerse a las previsiones de conflicto realizadas por los mandos noratlánticos ${ }^{15}$. Esta tónica se mantuvo hasta que comenzaron a aparecer en el horizonte, en torno a 1956, riesgos exclusivos de los regímenes de la Península que no podrían ser afrontados dentro de la estructura atlántica, como era el caso de los conflictos africanos, pero que sí podrían ser asumidos dentro del Pacto Ibérico.

Pasadas las grandes crisis de Corea y de Suez, y con las reformas en los sistemas defensivos tras la fundación del Pacto de Varsovia a raíz de la remilitarización de la República Federal de Alemania y su inclusión en la OTAN en 1955, los asuntos tratados en las reuniones militares peninsulares fueron adquiriendo unas dimensiones más propias de los problemas exteriores que podían llegar a afectar a la paz ibérica desde otras latitudes con la inquietud producida por la independencia del reino marroquí tras el fin del protectorado franco-español y sus inmediatas reivindicaciones terri-

14 Estas reuniones militares, en un principio, estaban enfocadas a la unificación de doctrina, uniformización de material y coordinación táctica en la defensa de la línea de los Pirineos y del Sur de Francia del enemigo proveniente del Este europeo dentro de los planes diseñados en París por el Mando Atlántico en Europa, SACEUR (Supreme Allied Commander Europe). El operativo configurado por los aliados anglosajones suponía para Portugal una doble aportación: la División SHAPE (Supreme Headquarters Allied Command Europe) destinada a la defensa de Francia integrada en un mando estadounidense, con base en Burdeos (sugerencia hecha por Franco y por el general Vigón a Salazar y Santos Costa en las conversaciones de Ciudad Rodrigo de 1952 y luego transmitida al mariscal Montgomery por este último en conversación posterior en Lisboa), y el Cuerpo Expedicionario Portugués (CEP) dentro de Ejército Vasco-Navarro español, destinado a la defensa conjunta de la línea pirenaica. Ambos ejércitos portugueses serían trasladados hasta sus respectivos puntos de concentración a través del territorio español por ferrocarril y por carretera, según las indicaciones militares de la Alianza y satisfechas las necesidades logísticas que suponían tanto la permanencia en territorio español del Cuerpo Expedicionario Portugués destinado a los Pirineos como las derivadas del operativo de traslado de las divisiones lusas destinadas a integrarse en las fuerzas de la OTAN en territorio francés.

Los acuerdos políticos para que la mencionada Divisão Nun' Álvares atravesara el territorio español fueron tomados en la Conferencia de Ciudad Rodrigo de 1952, donde se superaron las primeras renuencias presentadas por las autoridades militares españolas en 1951, seguramente para poder negociar su futura integración en la organización de defensa occidental, en la seguridad de que la OTAN necesitaba de esta autorización pues el traslado por mar del ejército portugués hasta Francia fue desde el principio descartado por el propio SACLANT (Supreme Allied Commander Atlantic).

${ }^{15}$ Las previsiones enunciadas por Washington en un primer momento contemplaban el peor escenario de guerra entre los bloques de la Guerra Fría: el rápido aplastamiento militar de toda la Europa continental, la evacuación para los extremos occidentales insular y peninsular y la organización de la resistencia en estos puntos para lanzar luego desde ellos una posible reconquista. En esta previsión, la integración de la España de Franco era inevitable a los ojos de los planificadores militares y el interés de los grandes estados en incorporarla a la Organización estuvo presente tanto en los procesos ordinarios como en las grandes citas noratlánticas en donde, una vez más, el portavoz de la necesidad de la incorporación española a la OTAN fue Portugal, siendo en alguna ocasión Oliveira Salazar personalmente el que abogó por ello cuando la cumbre tuvo lugar en Lisboa en febrero de 1952, poco antes del primer encuentro salmantino con Franco. 
toriales hacia Madrid, por una parte, y las presiones crecientes sobre los enclaves portugueses en el Indostán desde Nueva Delhi por otra. No podemos olvidar que tanto la Unión India como el Reino de Marruecos contaban con el apoyo de Washington que, como se comprobó enseguida, sacrificaba sin pudor sus amistades en la Península Ibérica ante las demandas de estos nuevos aliados, probablemente fruto de la conciencia del estado de debilidad en que se encontraban los regímenes políticos allí implantados y su dependencia de la protección anglosajona para sobrevivir.

Así, pasó a tener una importancia creciente, ya a partir de la VI CEMP en 1958, el tratamiento de los asuntos africanos, considerando que la naturaleza del enemigo era la misma para la que se había organizado una defensa peninsular conjunta pero su estrategia y su campo de acción diferentes. Fue entonces cuando el general Beleza Ferraz planteó los nuevos desafíos que llegarían a condicionar de manera sustancial la posición geoestratégica de la Península lbérica. Eran los provenientes de África, donde la penetración de la acción de los países del Este, según el máximo jefe de las Fuerzas Armadas portuguesas, estaba produciendo frutos que obligaban a mirar con atención redoblada al flanco sur peninsular. Se comenzó entonces a considerar que el Sahara había dejado de constituir una especie de océano separador que ofrecía seguridad a las costas mediterráneas frente a la creciente agitación nacionalista del África Negra. Además, en el norte de este continente se estaba políticamente construyendo «una carretera» que, en opinión del general portugués, podría transformar una eventual acción militar de la potencia del Este en una maniobra de fácil ejecución. En la misma reunión, por el lado español, el general Frutos Dieste asentía a las palabras de su homólogo portugués y manifestaba el convencimiento de su gobierno de que había que actuar en caso de necesidad con toda la energía posible.

La situación en la región norteafricana, en efecto, no se presentaba halagüeña para los estados ibéricos. La guerra de Argelia suponía un creciente esfuerzo de resistencia para Francia y estaba comenzando a provocar una grave división social en el país; en Egipto, Nasser se convertía, junto con Nehru y Sukarno ${ }^{16}$, vecino de colonias portuguesas en Asia, en la cabeza más brillante del movimiento afroasiático tras la Conferencia de Bandung y en triunfador sobre las viejas metrópolis coloniales desde el éxito de la Crisis de Suez; Marruecos y Túnez caminaban deprisa en el ejercicio de su soberanía y adoptaban políticas que se despegaban del pretendido neocolonialismo.

\section{LA AYUDA MILITAR DEL FRANQUISMO A LA GUERRA COLONIAL PORTUGUESA}

A partir de 1961 se empezaron a tratar en los puntos de agenda de las CEMP los asuntos relacionados con la guerra subversiva, incluyendo propuestas de realización

${ }^{16}$ Es necesario precisar que el Presidente de Indonesia, Sukarno, dio garantías a Salazar en su visita a Lisboa de que no alimentaba apetencias sobre Timor Oriental. 
de ejercicios conjuntos con este tema y con supuestos de acciones enemigas provenientes de África de los que el más amplio fue el «Ejercicio Salado», nombre dado en recuerdo de aquella batalla de la Reconquista en la que Portugal y Castilla habían unido sus fuerzas contra los benimerines del Norte de África en 1340. En ediciones posteriores se fueron añadiendo, como puntos permanentes, el análisis de la situación política en diversos estados africanos, tanto de su situación interna como de sus conexiones externas, así como el intercambio de información estratégica, producida por los servicios de información, sobre determinados estados del continente ${ }^{17}$. El acercamiento entre las estructuras de mando militar de la Península Ibérica llegó a tal nivel de proximidad en este aspecto que a partir de esta IV Conferencia de los Estados Mayores Peninsulares comenzó el intercambio de información en materia de "seguridad interior» entre la $3^{a}$ sección del Alto Estado Mayor de España y la $2^{\underline{a}}$ sección del Secretariado Geral da Defesa Nacional de Portugal y, más tarde, incluso llegó a funcionar normalmente un Procedimiento Acordado para Intercambio de Mensajes Cifrados de Instrucción entre ambas Fuerzas Armadas. En las conferencias posteriores, especialmente a partir de 1963, se le fue pidiendo un mayor esfuerzo a los servicios de información españoles.

Gracias a uno de los primeros objetivos de las CEMP, la unificación de armamento y la adopción de munición intercambiable entre los dos ejércitos peninsulares, a partir de 1959, Portugal pudo pasar pedidos de armamento fabricado en España, así como otros para la adquisición en condiciones muy favorables de medios indispensables para los movimientos de tropas en las largas distancias de Angola o Mozambique. De esta manera, se compraron las primeras doscientas cincuenta y seis unidades de camiones TT Barreiros Diesel para el Ejército portugués, vehículo que resultaba de gran interés para su uso en África porque, siendo potente y económico no era excesivamente pesado y presentaba la muy apreciable ventaja de ser apto para circular en sistemas rodoviarios deficientes, arenosos o enfangados, y montañosos con un declive superior incluso al $45 \%$. Podían muy bien, además, con los cañones de $105 \mathrm{~m} / \mathrm{m}$, que eran los destinados a las provincias ultramarinas, y con una carga hasta 2500 kg., para lo que estaban equipados con unos neumáticos especiales. Además, Portugal adquirió para sus Fuerzas Armadas el lanzagranadas INSTALAZA $88,9 \mathrm{~m} / \mathrm{m}$ del que realizó un primer pedido de mil unidades que fueron en parte enviadas al contingente destinado en la India y otras utilizadas en África por unidades paracaidistas y de infantería de Marina

Esto sucedía cuando ya se estaban preparando las adaptaciones militares para la guerra que se esperaba de un momento a otro en alguna de las colonias

17 La Comisión portuguesa solía pedir a la Comisión española información sobre Guinea-Conakry, Senegal, Congo-Brazzaville, Congo-Kinshasa, Zambia, Tanzania, República Árabe Unida (Egipto), Argelia y Marruecos. 
del África Occidental, bien Guinea con acciones desde la vecina Conakry, bien Angola, con apoyo del próximamente independiente Congo-Léopoldville ${ }^{18}$.

La Empresa Nacional Bazán construyó, expresamente encomendadas por Portugal para las necesidades de las guerras ultramarinas, siete corbetas entre 1969 y 1975 que fueron empleadas en los tres teatros de operaciones aunque con mayor intensidad en Mozambique. Se trató de tres navíos de la clase João Coutinho, la «Augusto Castilho», la «Honório Barreto» y la «António Enes» y cuatro de la clase Baptista de Andrade, más modernas pues contaban con direcciones de tiro con radar para abatir objetivos aéreos incluso en tierra, la «Baptista de Andrade», la «João Roby", la "Afonso Cerqueira» y la "Oliveira e Carmo». Todos estos navíos resultaron de gran utilidad en las operaciones realizadas durante la guerra en el Ultramar para la Marina portuguesa que había encomendado también navíos a la República Federal de Alemania.

España fabricó asimismo equipamiento para la Fuerza Aérea portuguesa, en concreto veintiséis aviones Aviocar C-212 que estaban destinados, como las corbetas, a los teatros de operaciones africanos para misiones tácticas, logísticas y evacuación de bajas. Con ellos se quería sustituir a los Dornier, DC3 y Noratlas que venían cubriendo en las colonias estas necesidades, sin embargo no llegaron a ser empleados en ellas por ser entregados en 1974 después del 25 de Abril.

Todas estas ventas a las Fuerzas Armadas portuguesas se hacían en las mismas condiciones que las estipuladas para el Ejército nacional por parte de los fabricantes españoles y más tarde se inscribieron en un Acuerdo de Compensación y Permuta que se gestó también en el seno de estas conferencias intrapeninsulares.

El Pacto Ibérico fue utilizado también durante las guerras portuguesas en África como manta bajo la que se abrigaba el auxilio militar en forma de apoyo logístico de diversa índole. Dentro de éste, además de las antes reseñadas, la modalidad más extraordinaria fue la venta de armamento de diversa naturaleza para su empleo en África proveniente de países que aparentaban mantener el embargo de suministros militares o incluso de otros estados que eran, al mismo tiempo, proveedores de las guerrillas implicadas en la contiendas, como algunos miembros del Pacto de Varsovia. El grueso de las importaciones se refería a municiones, seguidas de explosivos y, en último lugar, armamento ligero. Estas ventas, tratadas como parte de la colaboración militar dentro del Grupo Mixto de las CEMP, eran conocidas como "operaciones puente», compras de armamento con certificación de destino para las Fuerzas Armadas españolas que, una vez llegadas a España, eran embarcadas con destino a Lisboa.

18 En Lisboa se tenía información proveniente de fuentes oficiales, tanto internas como externas, por la colaboración prestada por otros servicios de información militar, de la inminencia de la deflagración de la guerra colonial desde, por lo menos, 1958. 
Dentro del apoyo logístico tuvo una particular importancia la utilización del aeródromo de Gando, en Gran Canaria, como escala en los vuelos militares entre Portugal y sus territorios africanos que se mantendría desde la primera operación, previa al inicio de las acciones armadas, en noviembre de 1960, de traslado para Angola de unidades PV2 de la Fuerza Aérea sin el consentimiento de la OTAN ${ }^{19}$, hasta 1973, cuando se suspendieron invocando razones de interés nacional ante el malestar de los países árabes por el apoyo logístico portugués a Israel contra la alianza árabe en la guerra del Yom Kippur. Las facilidades de uso de los aeródromos españoles respondían también a un acuerdo tomado en el seno de las CEMP, dentro de la coordinación de las fuerzas aéreas de ambos países que incluían el conocimiento mutuo de las respectivas instalaciones militares, además de formación y ejercicios conjuntos así como conexión de los sistemas de alerta aérea. El uso de este aeródromo fue especialmente útil cuando se prohibió el sobrevuelo de países africanos a las aeronaves portuguesas fruto de las rupturas de relaciones de los nuevos estados salidos de la descolonización para forzar un cambio de postura del gobierno de Lisboa respecto de sus colonias.

En el marco de las Conferencias de los Estados Mayores Peninsulares se redactaron diferentes documentos estableciendo convenios o acuerdos entre ambos estados en materia militar que serían promulgados y aplicados si llegara el caso de hacerlo necesario. El más destacable de ellos fue el Estatuto de las Fuerzas Armadas Peninsulares que en 1973 estaba aprobado y pendiente únicamente de firma y puesta en ejecución en el momento que resultase oportuno. Se trataba de un acuerdo, inspirado en el estatuto de las fuerzas de la OTAN, sobre el estatus jurídico que tendrían las Fuerzas Armadas de España y Portugal en sus respectivas actuaciones en el territorio vecino.

Se componía de un preámbulo y veinte artículos, el último de los cuales especificaba el ámbito de aplicación de los términos de la Convención «unicamente ao território peninsular, Açores, Baleares, Canarias e Madeira ${ }^{20}$ pero se le añadía esta posibilidad: "Qualquer das partes contratantes pode declarar contudo, por meio de notificação à outra parte contratante, que a presente Convenção se aplicará a quaisquer outros dos seus territórios. A presente Convenção será aplicada a esses territórios 30 dias após a recepção da notificação» ${ }^{21}$. Como vemos, las implicaciones políticas de este acuerdo suponían un elevado grado de compromiso en términos militares que abría la posibilidad de un alcance extra peninsular al Pacto Ibérico.

Se redactó también el Acuerdo de Apoyo Logístico que, por estas mismas fechas, estaba pendiente de ser rubricado por las autoridades respectivas en el momento adecuado. También las Normas para los Encargos de Material de Gue-

\footnotetext{
19 Ver SILVA CARDOSO, A., Angola, anatomía de uma tragédia, Cruz Quebrada-Oeiras, Oficina do Livro, 2005, p. 31-80.

${ }^{20}$ Estatuto das Forças Armadas Peninsulares, AHM F.7 Sr.65 Caja 90.

${ }^{21}$ Ibídem.
} 
rra a adquirir en Portugal por España y en España por Portugal se encontraban en condiciones de entrar en vigor cuando se preparaba la visita de Carrero Blanco a Lisboa a finales de 1973. Este año fue el principio del fin de la guerra colonial para Portugal pues se sumaron un recrudecimiento de la situación militar en Guinea y la declaración de independencia de Madina de Boé, que enseguida comenzó a recibir reconocimientos diplomáticos, con las nefastas consecuencias del apoyo logístico brindado por el gobierno de Caetano a las fuerzas americanas de auxilio al Israel colapsado por el ataque de la coalición árabe en el Yom Kippur²2. El apoyo de los Estados Unidos empezó a tener dificultades añadidas por la especial debilidad del presidente Nixon tras el estallido del escándalo Watergate y las alianzas con los estados racistas del África Austral no conseguían compensar las pérdidas de los apoyos en el resto del mundo.

En este delicado momento para el gobierno de Caetano, asumía en España el puesto de ministro de Asuntos Exteriores el lusófilo López Rodó, nombrado en el gabinete que formó Carrero Blanco al asumir la Presidencia del Gobierno en junio de 1973. El nuevo ministro español se puso inmediatamente a desarrollar un ambicioso programa de aproximación a Portugal que tenía como objetivo añadido al mantenimiento de la tradicional amistad ibérica que habían establecido Salazar y Franco la ampliación del mercado español aprovechando el impulso económico pretendido por los tecnócratas portugueses en los planes de desarrollo tanto metropolitano como colonial. Programa que ya había iniciado, en parte bajo sus indicaciones, su antecesor Gregorio López Bravo.

En el viaje de Caetano a Madrid en 1970 se había ratificado el Pacto Ibérico con gran solemnidad y los encuentros de Salazar y Franco que habían mantenido la amistad peninsular comenzaron a ser sustituidos por encuentros regulares de carácter técnico-político, como correspondía a esta modalidad de gobiernos. Portugal intentó la firma de un protocolo secreto al mismo tiempo que se sumaba al Pacto el Tercer Protocolo Adicional. Se empezaron así a suceder las visitas alternadas entre los respectivos ministros de Asuntos Exteriores y a multiplicarse los encuentros de comisiones técnicas, manteniéndose las que se venían sucediendo en la cúpula militar, las CEMP, en los mismos términos de siempre. En este contexto de continuidad renovada tras la desaparición política de Oliveira Salazar, estaba prevista la visita a Lisboa del almirante Carrero Blanco, cuando el atentado que le costó la vida lo impidió.

En el clima especialmente delicado de 1973, tanto de la situación internacional, en impaciente espera del fin de la guerra de Vietnam y con la presidencia de los Estados Unidos a punto de caer, como peninsular, con los problemas africanos y los de la oposición interna creciendo, debió de producirse alguna filtración de las intenciones portuguesas en busca de una mayor implicación española pues apare-

22 Ver FREIRE ANTUNES, Portugal na guerra do Petróleo. Os Açores e as vitórias de Israel 1973. Edeline, Versalles, 2000. 
cieron alarmas en la prensa internacional, especialmente entre los círculos católicos europeos, que podrían estar relacionadas con la última cláusula del Estatuto de las Fuerzas Armadas Peninsulares antes citado. Así, el Volkskrant, diario católico de Ámsterdam, publicaba el seis de abril de 1973 una noticia desde Tananarive recogiendo las declaraciones de Burgess Car sobre la existencia de un «pacto bilateral» en virtud del cual «se podría llamar la ayuda de soldados españoles en las colonias de Portugal en África» ${ }^{23}$. También alguna prensa africana, como el Liberian Age, extendió el mismo rumor aunque nada se tradujo en la prensa española e incluso en la Conferencia de Técnicos sobre Apartheid y Discriminación, organizada por las Naciones Unidas en Oslo, se pretendió que España estaba obligada a una colaboración militar en África como consecuencia del Pacto Ibérico.

Ante la amplitud que iba tomando el rumor enseguida se cursaron instrucciones desde Madrid a las legaciones españolas para ayudar a las cancillerías a darles una respuesta puntualizando que el único acuerdo existente entre España y Portugal era el Tratado de Amistad y No Agresión de 1939 y que éste circunscribía su ámbito de aplicación a los respectivos territorios metropolitanos. La extensión de los rumores llegó a producir inquietud en la diplomacia española, consciente de los peligros que entrañaba una difusión pública de las ayudas españolas a las guerras africanas de Portugal como pone de relieve este párrafo : «Dejar correr esta especie en nada beneficia a Portugal, sino que más bien le perjudicaría al hacer más incómoda nuestra ayuda constante, decidida, si bien discreta en asuntos relacionados con su defensa, y la posición española sería perjudicada tal vez seriamente».24

¿Encontramos aquí una muestra de lo que podría equivaler a aquel «apoyo militar modesto» que Salazar brindó a Franco en la Guerra Civil? ¿podríamos considerar mucho más comprometida esta colaboración en un momento en que, con tres frentes de guerra abiertos, el embargo internacional podía mermar la eficacia de las operaciones militares portuguesas en sus colonias?

Es conocida la contribución francesa y también la alemana en el ámbito de la provisión de armamento para la guerra del Ultramar portugués, de mayor volumen y especial valor ante el retraimiento anglosajón, compensadas ambas con permisos de asentamiento militar en territorio luso, base de Flores, en las Azores, y base de Beja ${ }^{25}$, en el Alentejo, respectivamente. Del mismo modo fue de gran valor, estratégico y táctico, el apoyo en todos los campos de Rodesia y, sobre todo,

${ }^{23}$ Estas declaraciones fueron hechas ante el Comité General de la All-Africa Conference Churches, organización en el que participaban ciento tres iglesias procedentes de treinta y un países de África. La Iglesia católica, sin embargo, no era miembro.

${ }^{24}$ Carta «personal y reservada» del 21 de junio de 1973 al embajador de España en Lisboa, Emilio Navasqüés, AMAE, R. 15158, ex. 7.

${ }^{25}$ La base de Beja se instaló en Portugal tras haber fracasado las negociaciones secretas hispanogermanas, que se venían realizando desde la visita de Castiella a Bonn en el otoño de 1959, por intervención de la cúpula política y militar de la OTAN, contraria a un acercamiento alemán a España y que utilizó la prensa internacional para alarmar sobre los peligros que suponían estos intentos «que recuer- 
de África del Sur. En menor medida, contribuyeron también al esfuerzo de guerra portugués en sus colonias africanas otros estados como Italia. Las inversiones que se realizaban en las obras de desarrollo de estos territorios, entre las que destacan las grandes construcciones como la presa de Cahora-Bassa en Mozambique, podrían igualmente ser consideradas una importante ayuda desde el momento en que formaban parte de la estrategia del gobierno de Lisboa por mantenerse en el continente.

Pero es preciso tener en cuenta que estas aportaciones se dan por parte de unos estados con una posición de fuerza y solidez en el concierto de las naciones muy superior a la del régimen español siempre amenazado de reveses diplomáticos como se vio en los que acompañaron sus dos últimos años de existencia.

\section{LOS APOYOS DIPLOMÁTICOS DEL FRANQUISMO A LA GUERRA COLONIAL PORTUGUESA}

Además de la ayuda militar en forma de soporte logístico, el apoyo diplomático ofrecido por España revistió niveles poco frecuentes al incluir la cobertura de repetidas operaciones de desestabilización para mudanza de regímenes políticos o de gobernantes en países africanos directamente relacionados con las colonias portuguesas, particularmente con Angola. La alianza de supervivencia política Franco-Salazar fue nuevamente la base de las facilidades y, en especial, de la protección político-diplomática que, decretada desde el Pardo, fue ejecutada en diferentes misiones españolas cuando el ambiente internacional se tornó amargo para Portugal a causa de su pertinaz oposición a la descolonización. Una paciente labor obstruccionista de las condenas a Portugal en los areópagos multilaterales, especialmente en las Naciones Unidas, un apoyo discreto en terceros países y una cobertura total en los estados africanos donde España se hizo cargo de la representación de los intereses portugueses son los tres campos de esta acción exterior en apoyo de la posición portuguesa durante las guerras en África.

No obstante las tensiones que constantemente se producían en los niveles intermedios de los gobiernos a partir de la divergente posición frente a los procesos de descolonización, el entendimiento en las alturas se mantuvo y se estrechó con el comienzo de la contienda en Angola en 1961 que, recordemos, fue acompañado en Portugal de contundentes manifestaciones desde el estamento militar contra la política gubernamental ultramarina traducidas en el frustrado golpe del ministro de la Defensa, Júlio Botelho Moniz.

Apenas pasados tres días de la fallida "Abrilada», el 16 de abril, Franco envió una carta personal manuscrita a Salazar en la que, además de expresarle la más

dan sus repelentes vínculos con la Alemania de Hitler», New York Times, editorial de 22 de febrero de 1960, traducción MAE, OID Prensa, RAH/AC, 914. 
leal e intensa adhesión de España, le ofrecía la más amplia, entusiasta y firme colaboración "en cuanto podamos facilitaros vuestra accion (sic)» 26 . La respuesta del Presidente del Conselho portugués, tres meses y medio después, es igualmente elocuente de este entendimiento. Salazar admitía la eventual necesidad de la ayuda española y agradecía la oferta «Absolutamente confiados na sua promessa, continuamos a contar com esse apoio - ser-nos-á necessário contar com ele. [...] Nós, portugueses, vamos sentir en toda a parte dificuldades sérias [...] Certamente a luta é extraordinariamente difícil e custosa; nem podemos convencer-nos de que por ora estamos aptos a lutar eficazmente contra tal género de guerra [...]. Todos aquí temos a maior confiança no apoio e ajuda que pela Espanha Vossa Excelência nos promete ${ }^{27}$. En esta carta, Salazar hacía mención expresa de un punto determinante para el conflicto portugués: "Salvo o caso de a Rússia poder vir a dominar a política do Congo, e daí dominar o resto da África sob influência ocidental, as coisas hão-de ir pouco a pouco melhorando» ${ }^{28}$.

La cobertura que para la neutralización de la región del Congo, tanto el antiguo territorio belga como el francés, se dio desde la embajada de España en Kinshasa respondía a esta necesidad pues el gran interés de Portugal era tratar de impedir la existencia de santuarios al lado de su frontera angoleña que ofrecieran una retaguardia segura a las guerrillas del MPLA y de la UPA. Imposibilitar una unidad de acción de ambas facilitada por el entendimiento entre los dos estados de acogida se convirtió en otra prioridad de la acción portuguesa en el África central. Disponer de información estratégica para llevar a la práctica estas líneas de acción prioritarias suponía disponer de redes de información que podían actuar con mayor seguridad contando con inmunidad diplomática. Por ello, Lisboa extendió, a partir de sus embajadas en África, redes de tal valor militar en una guerra subversiva que llegaron a ser consideradas determinantes para «la capacidad de Portugal de sustentar el conflicto durante trece años y utilizar sus limitados recursos en el control de la amenaza de la guerrilla» $29 \mathrm{y}$, en concreto, algunos analistas del momento ya consideraron que «las redes de la PIDE y los informadores portugueses en el Congo-Kinshasa son equivalentes en su efecto a una división de paracaidistas en el suelo» ${ }^{30}$.

Cuando se produjo la cascada de rupturas diplomáticas con Portugal por parte de estados africanos a partir de la Conferencia de la OUA de Addis Abeba, en 1963 , la necesidad de Lisboa de tener un nexo diplomático con algunos de aquellos países aumentó. España, a solicitud del ministro Franco Nogueira, asumió inmediatamente la representación de los intereses portugueses en algunas embajadas africanas, en el Egipto de Nasser y en el Túnez de Bourguiba, pues en las Neces-

${ }^{26}$ Correspondencia relativa a España. 1943-1966. IANTT/AOS/COE-2.

27 Ibídem.

28 Ibídem.

${ }^{29}$ Ver CANN, J. P., Contra-subverção em África. Como os portugueses fizeram a guerra em África. 1961-1974, Lisboa, Prefácio, 2005.

30 PELISSIER, R. y WHEELER, D. L., Angola, Londres, Pall Mall Presse, 1971, p. 216. 
sidades se consideró que España, por su amistad con los países árabes, sería el país más indicado para ejercer esta función. Más tarde, en 1966, haría lo propio en el Congo-Kinshasa tras la ruptura decidida por Mobutu al conocer los planes de un golpe para derrumbarlo en los que estarían implicados diferentes servicios entre los que se encontraban los portugueses.

A través de estas representaciones diplomáticas españolas, Portugal trató de mantener contacto con los gobiernos respectivos y con las legaciones de otros estados y además ampliar la operatividad de sus redes de información con funcionarios de la carrera diplomática y de los servicios policiales. En algún caso se llegó a acreditar con estatus diplomático un miembro de la PIDE/DGS bajo la cobertura de secretario de la embajada de España. Así sucedió en Kinshasa, desde donde su acción se irradió también hacia Brazzaville, cuyo régimen acogía al MPLA. La neutralización de éste en el Norte resultó indispensable para el mantenimiento del equilibrio militar en Angola cuando se presentó la necesidad de redoblar el esfuerzo militar con la apertura del frente Este. También desde la embajada de España en Kinshasa se proyectaba la acción de las redes de información hacia Zambia y Tanzania, para apoyo del frente mozambiqueño.

Existía asimismo un componente que sirvió de apoyo a la estrategia portuguesa de intervención en estados africanos (habitualmente en conjunción con servicios de otros países) para la que Madrid se convirtió en estos años en retaguardia operacional. Además de centro de reclutamiento de mercenarios y de acción de organizaciones tapadera de las operaciones especiales en África (caso de la Aginter Press \& Presse con sede en Lisboa y una extensión en Madrid), España era lugar de acogida de algunos políticos africanos pro-occidentales defenestrados y especialmente inclinados a la colaboración con el Portugal salazarista. Los casos más significativos fueron el Abate Youlou, depuesto presidente del Congo-Brazzaville, o de Moïse Tshombé, artífice de la secesión katangueña y después Primer Ministro del Congo-Léopoldville. Desde la capital española, a medio camino entre Lisboa y París, se trazaron algunas de las operaciones destinadas a lograr la reposición en el poder de estos gobernantes caídos que contaban al mismo tiempo con la protección directa del Estado español, con la benevolencia del Estado francés y con un generoso apoyo del Estado portugués.

La diplomacia española relacionada con los asuntos portugueses en África sufrió gran inquietud por los efectos que este apoyo podía llegar a tener, además de en los propios estados africanos que alguna vez llegaron incluso a amenazar a Madrid con la ruptura de relaciones, en los foros internacionales, particularmente en la ONU.

Fue en este centro esencial de las relaciones multilaterales donde se llevó a cabo el apoyo más visible de la diplomacia española a Portugal durante la guerra colonial. Fue también sobre esta actuación donde recayeron las quejas más frecuentes del gobierno de Lisboa, especialmente acres en la etapa de Franco Nogueira, y a las que la diplomacia española respondía doliéndose del poco aprecio 
que recibían algunas actuaciones como la del ministro de Asuntos Exteriores, Fernando Castiella, el 24 de septiembre de 1964, ante el pleno de la Asamblea General de la ONU. De hecho, Oliveira Salazar sí agradeció el gesto del ministro español enviando una carta manuscrita al embajador de España en Lisboa en la que elogiaba expresamente el discurso de Castiella, sobre todo por la «inteligente y documentada defensa de los derechos de Portugal $\gg .{ }^{31}$

De la misma manera, la amistad de los estados hispanoamericanos, que era una de las líneas de acción prioritarias en la política exterior del gobierno español, fue apurada al máximo para obtener su apoyo a los intereses portugueses por medio de gestiones ordenadas directamente desde Madrid. Las instrucciones que recibía la Representación Permanente de España ante las Naciones Unidas, y que cumplía muy a su pesar, solían responder a peticiones concretas del gobierno portugués, como vemos en este ejemplo de los primeros momentos de la guerra en Angola tras los acontecimientos de Luanda del 4 de febrero de 1961:

"Gobierno portugués ha solicitado gobierno español haga gestiones cerca de Chile y Ecuador para que sus delegados en Consejo Seguridad apoyen actitud portuguesa oposición inclusión asunto Angola en orden del día Consejo de Seguridad por razones siguientes: ser asunto interno y de su plena soberanía; las alteraciones ahí producidas no son peligrosas para la paz mundial; y la mayor parte de los causantes eran gente llegada de fuera. Gobierno portugués estima tiene número suficiente de votos en Consejo Seguridad para rechazar propuesta rusa. Debe V. E. seguir contacto con embajador de Portugal y realizar gestiones correspondientes.» 32

El entonces delegado adjunto de esta Misión, Jaime de Piniés, conspicuo defensor del despegue de España de la política colonial portuguesa por los perjuicios que causaba a los intereses españoles en el ámbito multilateral, respondió a su ministro informándole de las dificultades que le habían expresado los delegados de los gobiernos aludidos para manifestar abierto apoyo a Portugal acusado de «sistemático desconocimiento derechos humanos en Angola», por la exacerbada represión con que respondió a los asaltos de las prisiones de Luanda. Pese a las reticencias de los sudamericanos y de que conocía la determinación del grupo afroasiático a presionar para conseguir que el Consejo de Seguridad tratara los acontecimientos de Angola, Piniés cumplió las instrucciones recibidas aún sin convicción ${ }^{33}$.

Dada la mudanza producida en la política exterior norteamericana ya antes de la llegada de Kennedy a la Casa Blanca y la enemistad que se generó entre Washington y Lisboa en este primer momento, la mayoría de las delegaciones latinoamericanas en las Naciones Unidas se encontraban en muy delicada situación para ofrecer apoyos a Portugal. Por su parte, Francia, empantanada en Argelia y

\footnotetext{
${ }^{31}$ Borrador de carta de Salazar al embajador de España, Ibáñez Martín, IANTT/AOS/COE-2.

32 Telegrama cifrado del Ministro Castiella al Delegado de la Misión de España ante la ONU de 21 de febrero de 1961, RAH/AC 1259/3.

${ }_{33}$ Telegrama reservado de Jaime de Piniés para Castiella de 21 de febrero de 1961, RAH/AC 1259/3.
} 
con sus fuerzas armadas divididas a propósito de la solución a este conflicto, no ofrecía seguridades de apoyo a Portugal aunque las deseara y solía quedarse, en el mejor de los casos para el gobierno de Lisboa, en la abstención. Gran Bretaña, además de seguidora de la línea política de los Estados Unidos, tenía sus propios problemas en el África Austral, para los que no resultaba favorable aparecer alineada con la política integracionista de Lisboa. España por norma o se abstenía o votaba a favor de Portugal, «con graves perjuicios en muchas ocasiones» ${ }^{34}$ cuando se trataba de ataques directos a las actuaciones portuguesas en los órganos centrales de las Naciones Unidas. En el caso de las embestidas indirectas contra la política colonial portuguesa, los representantes españoles votaban «a favor o en contra de las Resoluciones, según sus propios méritos, pero siempre en contra de los párrafos que pudieran molestar a Portugal» 35 .

La diplomacia española, en su afán de conjugar la amistad peninsular con la cautela necesaria para no granjearse enemistades en el grupo afroasiático, cuyo apoyo necesitaba en las resoluciones relativas a Gibraltar, realizó un esfuerzo constante de explicación de su toma de postura en cada ocasión que la política portuguesa resultaba concernida. Al mismo tiempo, trataba de hacer comprender al gobierno portugués que, desde un punto de vista práctico, era esencial que España mantuviera las simpatías de estos países, cuyo número iba aumentando en el concierto internacional a medida que avanzaba el proceso descolonizador, para poder seguir brindando apoyo a Portugal. Como vemos, se utilizaba en esta ocasión el mismo argumento usado por el gobierno portugués a propósito de la exclusión de España de la OTAN.

En este sentido, en 1960, año en que se evidencia la divergencia peninsular frente a la descolonización, el subsecretario de Política Exterior, Ramón Sedó Gómez, fue enviado a Lisboa a explicar al entonces ministro, Marcello Mathias, la posición española frente al Tercer Mundo, y, desde entonces, las explicaciones a los portugueses se fueron multiplicado. Después de las reuniones de la Asamblea General, o de otras organizaciones internacionales, diplomáticos españoles iban a Lisboa a explicar la actuación de los representantes del gobierno de España en Nueva York. Así por ejemplo, en diciembre de 1968, recién llegado Caetano al poder, el director general de Europa, Fernando Olivié González-Pumariega, aclaró en Lisboa, al parecer satisfactoriamente, la política desarrollada por España en la Asamblea General de las Naciones Unidas.

Sin embargo, el esmero de la diplomacia española por dar todo tipo de explicaciones no era suficiente para satisfacer las demandas portuguesas y ante las repetidas manifestaciones de malestar portugués, en Madrid se hacían compara-

34 Nota Informativa del 19 de mayo de 1969 de la Dirección General de Asuntos de Europa del Ministerio de Asuntos Exteriores, AGA (10) 73 54/06692.

35 Ibídem. 
ciones con la «comprensión» hacia la postura de los aliados tradicionales de Portugal, en especial hacia Gran Bretaña:

«Estas aclaraciones y la limpieza de nuestra política no han evitado una postura de queja frente a nuestro país, olvidándose de la ayuda práctica que recibe y de los esfuerzos que por Portugal hacemos protegiendo sus intereses en países que han roto con Lisboa (Países árabes, Congo-Kinshasa, etc.). Pero es que para Franco Nogueira, España tiene que hacer lo mismo que Portugal y arrostrar conjuntamente con Lisboa el aislamiento internacional y los tiros en Ultramar. Portugal no pide esto a Inglaterra, la vieja aliada de Portugal, y no parece entender que es además miembro de la NATO encontrándose por tanto protegida en la defensa de algo que constituye lo más importante de su ser nacional. España, en cambio, está al margen de Europa y debe hacer continuos equilibrios diplomáticos desde hace casi veinticinco años para sobrevivir como nación digna e independiente» ${ }^{36}$.

España ofrecía igualmente de manera permanente su capacidad para hacer de mediador siempre que fuera por expreso pedido de Lisboa. En este apartado se pueden incluir algunas solicitudes portuguesas de mediación española como la efectuada en julio de 1963 para que Franco tratara con Hassán II de Marruecos en la entrevista de Barajas la inconveniencia de una eventual ruptura de relaciones con Lisboa. De hecho, Marruecos fue una de las pocas legaciones que Portugal mantuvo en África, donde tenía una red diplomática mucho más extensa y antigua que España, pues era precisamente en este momento cuando Madrid la estaba comenzando a extender más allá de la vertiente mediterránea del continente, que era su espacio de acción tradicional.

¿Podemos ver en esta especial cobertura político-diplomática una compensación de la que el régimen salazarista proporcionó al bando franquista en los años treinta?

\section{CONCLUSIONES}

De todo lo expuesto podemos concluir que, al igual que el Portugal salazarista se prestó a ser el apoyo y la ventana del Franquismo en sus momentos de mayor dificultad en el sistema internacional, la España franquista se convirtió en la ventana y el apoyo del Estado Novo en el periodo de grandes dificultades derivadas de su política de mantenimiento del imperio. La aportación española al esfuerzo de guerra de Portugal entre 1961 y 1974 se mantuvo desde la primera oferta que Franco hizo a Salazar en su carta de 1961 y se llevó a efecto, a pesar de tomar una opción diferente en la política exterior de cara al proceso de descolonización, en todos los ámbitos en donde Portugal reclamó colaboración, en el político-diplomático y en el militar, con los servicios de información como valor común a ambos,

\footnotetext{
36 Nota Informativa del 19 de mayo de 1969 de la Dirección General de Asuntos de Europa del Ministerio de Asuntos Exteriores, AGA (10) 73 54/06692.
} 
con el único límite de la defensa de los grandes intereses nacionales, especialmente los ligados a la reivindicación de Gibraltar y a la salvaguarda de la amistad con los países árabes.

El Pacto Ibérico fue el instrumento jurídico-político en el que se escudó el apoyo del Franquismo a la política africana del Estado Novo para lo que su ámbito se fue sucesivamente ampliando a partir de la inserción española en la estrategia de defensa de Europa diseñada por la OTAN en la cual la colaboración española resultaba indispensable por la necesidad de contar con la autorización y la ayuda logística para el paso de las tropas portuguesas destinadas a ese operativo (División SHAPE) y para la defensa conjunta de la Península en los Pirineos en la que se integraría un Cuerpo de Ejército Portugués (CEP).

La coordinación militar, establecida a través de las anuales Conferencias de los Estados Mayores Peninsulares por las necesidades de la Alianza Atlántica, fue el marco jurídico-político donde también se insertó la contribución militar española para subvenir a las necesidades de Portugal en la guerra colonial. El interés de Franco por integrarse en la organización político-militar de defensa de Occidente justificaría la inicial puesta en marcha de estos mecanismos a partir de 1952, aunque el veto político de los estados nórdicos europeos hubiese impedido la consecución de este objetivo.

Pero, más allá de los paralelismos entre las ayudas recíprocas entre Salazarismo y Franquismo, encontramos una diferencia notable entre ambos casos: la ayuda portuguesa al bando franquista durante la Guerra Civil se asistió de un primordial aparato de propaganda propio de los años treinta, mientras que el apoyo español en la guerra ultramarina portuguesa se mantuvo en la más absoluta discreción. Esta importante diferencia creemos que se puede explicar por dos razones: por la naturaleza misma de la ayuda española y por la divergencia de los intereses de cada uno de los regímenes ibéricos en la coyuntura histórica de la descolonización africana, situación inversa a la convergencia de beneficios que se esperaba se derivarían, tanto para el Portugal de Salazar como para el bando de Franco, de una victoria militar y política en tierras españolas en los años de ascensión de los fascismos.

\section{FUENTES ARCHIVÍSTICAS}

Archivo General de la Administración, Alcalá de Henares (AGA). Archivo Castiella, Real Academia de la Historia, Madrid (RAH/AC). Instituto dos Arquivos Nacionais Torre do Tombo/ Arquivo Oliveira Salazar, Lisboa (IANTT/AOS). Archivo del Ministerio de Asuntos Exteriores Renovado (AMAE, R.).

Arquivo da Defesa Nacional, Oeiras (ADN). Arquivo Histórico-Militar, Lisboa (AHM). 